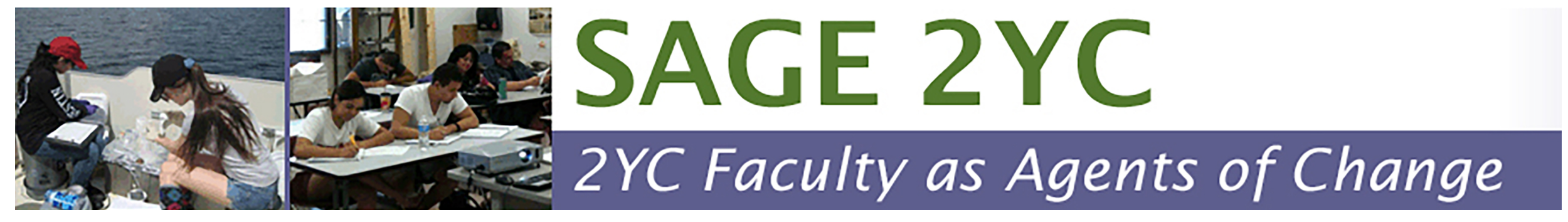

\title{
Diversity, Equity, and Inclusion: SAGE 2YC Resources for the Geoscience Community
}

\author{
Carol J. Ormand, SERC, Carleton College \\ R. Heather Macdonald, Geology, College of William and Mary \\ Eric Baer, Geology, Highline College \\ Rachel Beane, Earth and Oceanographic Science, Bowdoin College \\ Jan Hodder, OIMB, University of Oregon \\ John McDaris, SERC, Carleton College \\ Kristin O'Connell, SERC, Carleton College
}

This work is supported by the National Science Foundation through grants $1525593,1524605,1524623 \& 1524800$.

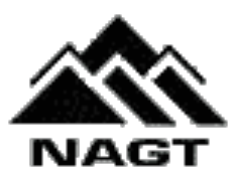




\section{Overview}

- The SAGE 2YC: Faculty as Change Agents project

- Project resources for the geoscience community

- Materials for professional development workshops

- Diversity in action: Broadening participation through strategies for inclusion

- Supporting students' sense of belonging

- Building students' science identity

- SAGE Musings

- Growing collection of $>50$ posts, 18 of which are relevant to broadening participation in STEM
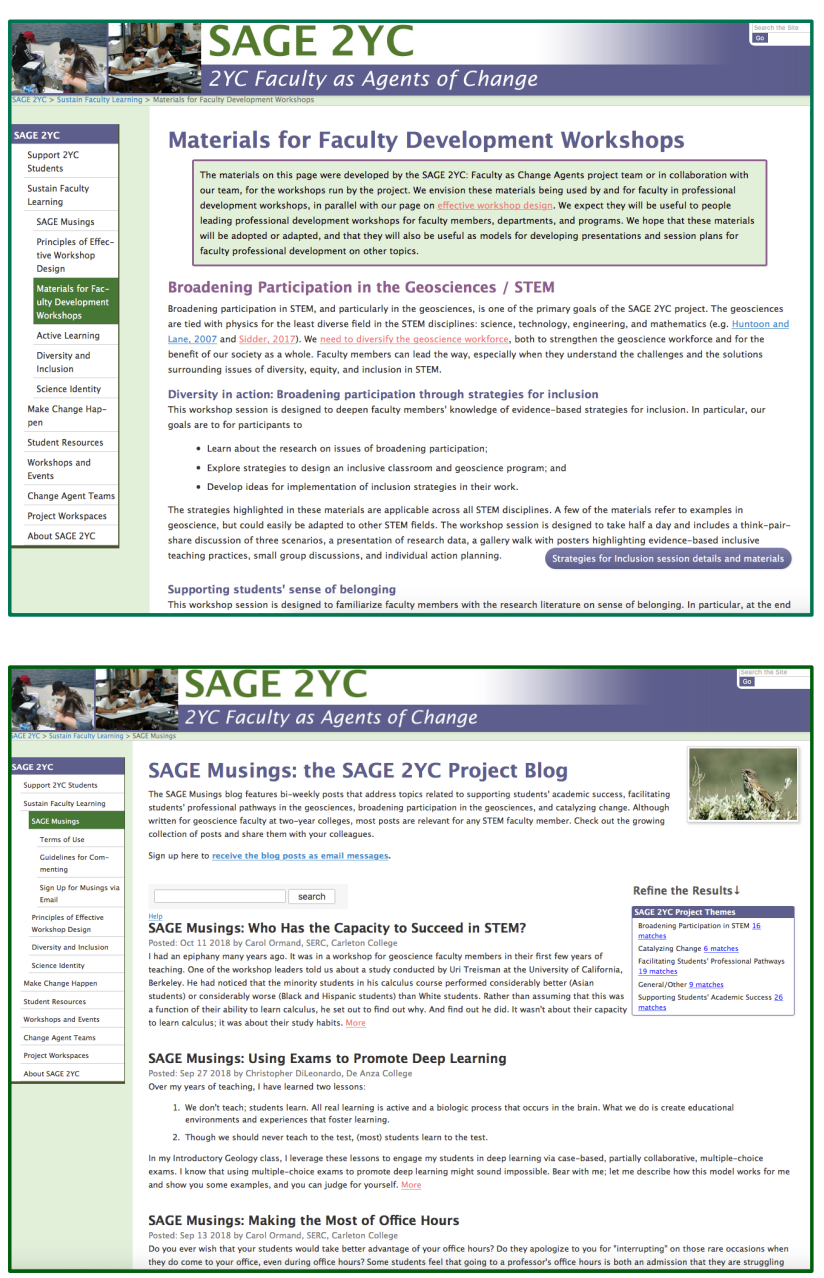


\section{SAGE 2YC: Faculty as Change Agents project goals}

- Build a sustainable national network of 2 YC leaders (change agents) who catalyze change at multiple levels from their courses to institutions in their local regions and within the community of practice;

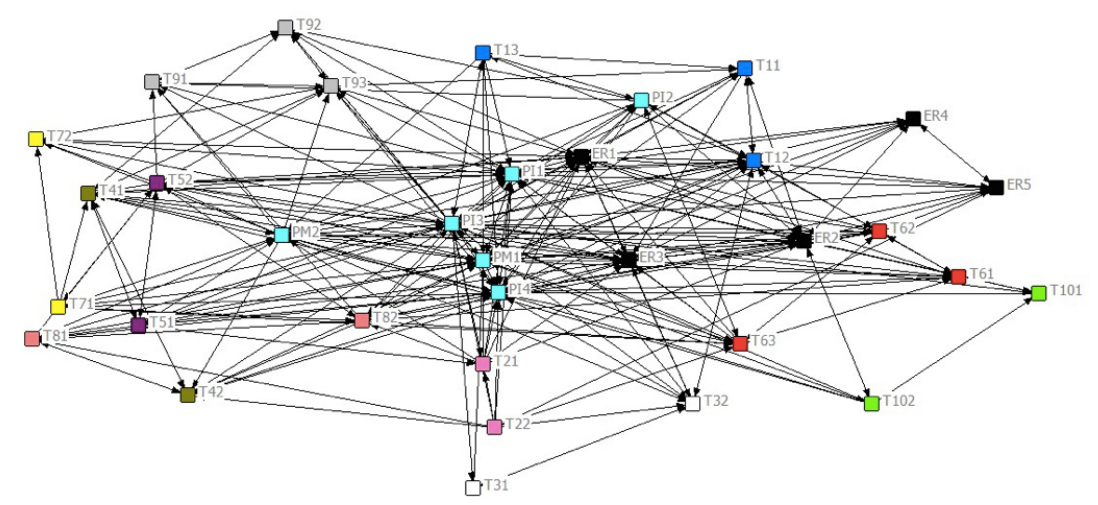

- Implement high-impact evidence-based instructional and co-curricular practices that support the academic success of all students, broaden participation, and promote students' professional pathways into geoscience; and

- Investigate models of professional development for full-time and adjunct 2YC geoscience faculty that promote the cycle of innovation, where faculty learn from the research of others, make changes in their own practice, and share what they have learned with the education community. 


\section{SAGE 2YC project resources}

- Incorporate research into practice

- Promote and support the participation, success, and continuation of a diverse population of students in geoscience courses, programs, and careers

- Promote a culture of diversity, equity, and inclusion at institutional and national scales

- Model transformative change in academia

- Are designed for re-use

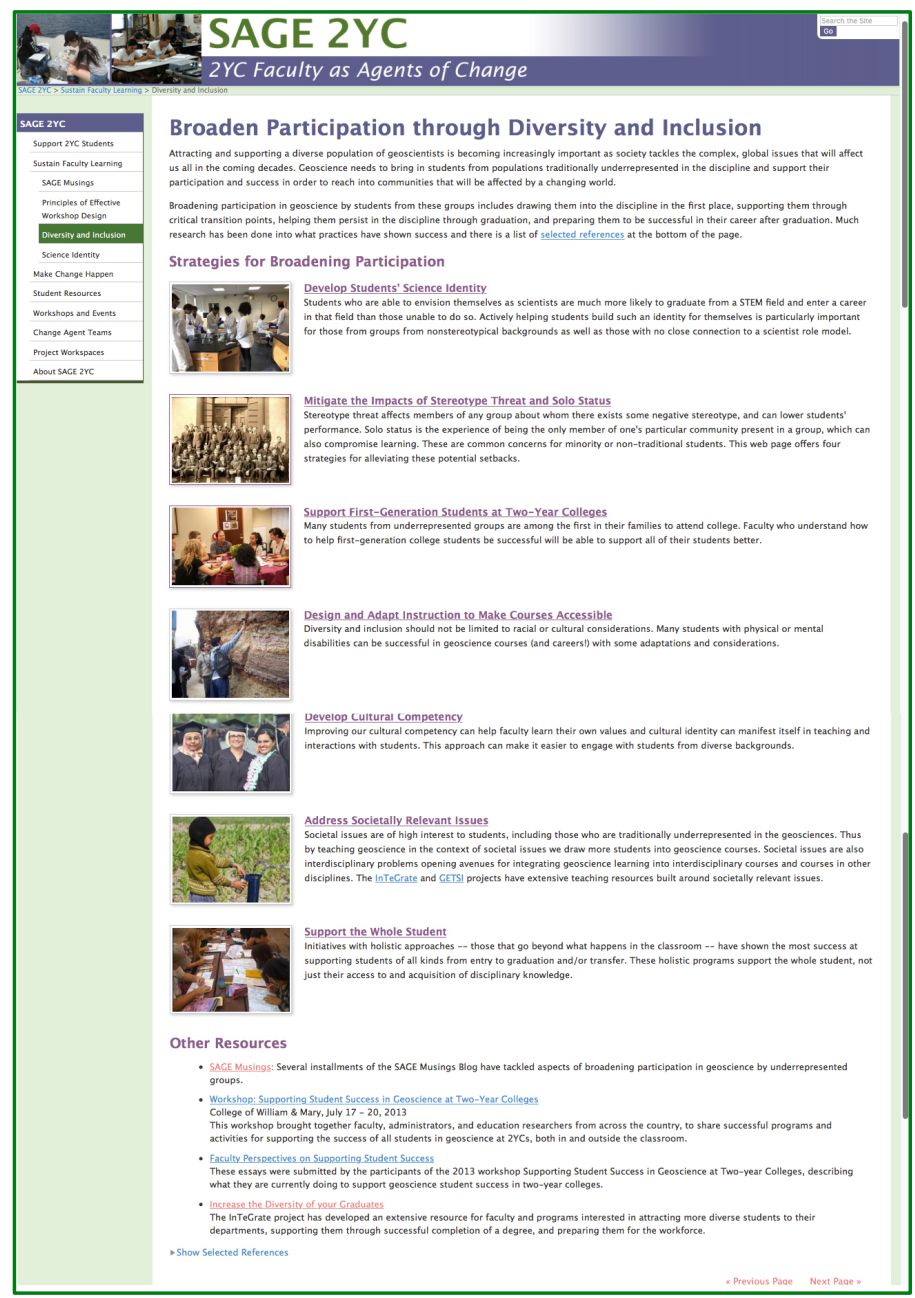




\section{Materials for professional development workshops}

Developed for our SAGE 2YC faculty workshop sessions

- Diversity in action: Broadening participation through strategies for inclusion

- Supporting students' sense of belonging

- Building students' science identity

Follow the principles of effective workshop design:

- Session activities follow directly from the goals

- Participants are actively engaged in learning

- Materials and activities are evidence-based

- Sessions are planned to the minute, including time for reflection and action planning

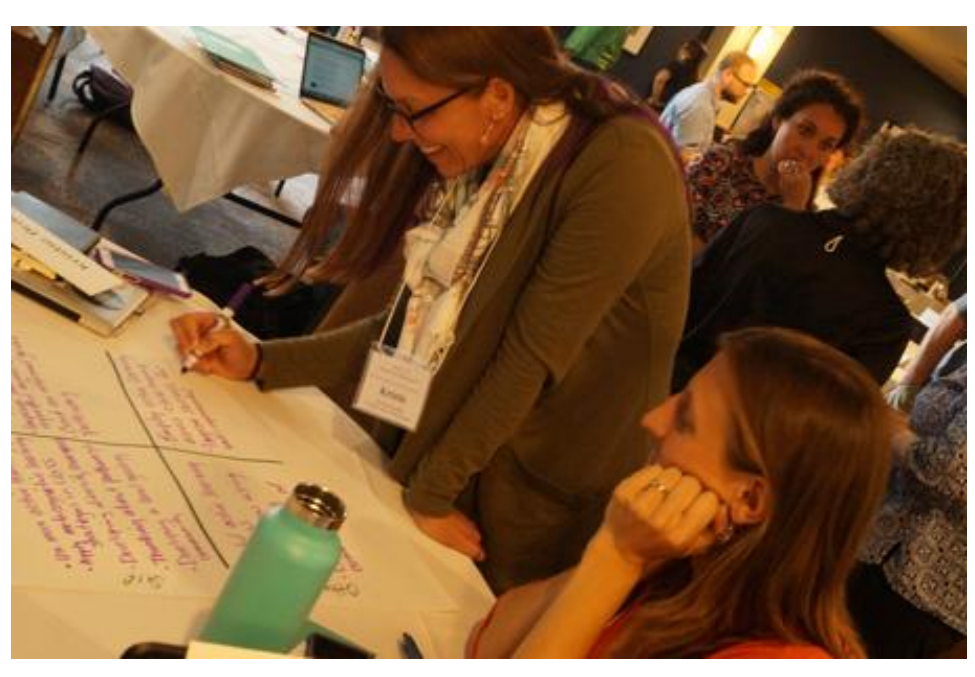




\section{Diversity in action: Broadening participation through strategies for inclusion}

Session goals: Participants will

- Learn about the research on issues of broadening participation;

- Explore strategies to design an inclusive classroom and geoscience program; and

- Develop ideas for implementation of inclusion strategies in their work.

Workshop session structure and materials:

30 minutes Think-pair-share discussions: scenario

20 minutes Presentation: research on the lack of diversity in geoscience \& STEM

50 minutes Gallery walk: Posters about strategies for inclusion, followed by

60 minutes In-depth small group discussions

40 minutes Action planning 


\section{Diversity in action: Broadening participation through strategies for inclusion}

Think-pair-share discussions about scenarios

Demoralized by my colleagues

Our college is recognized as a Hispanic-serving Institution but rarely do we see Hispanic students in the geoscience courses. Knowing that diversifying the geoscience work force is a national priority I asked to have this topic added to the agenda of our upcoming departmental meeting. I presented some information on this issue that I found on the AGI website and suggested that we think of ways to encourage Hispanic students to take our courses. [Colleagues' responses were less than enthusiastic....] 


\section{Diversity in action: Broadening participation through strategies for inclusion}

Presentation: research on the lack of diversity in geoscience \& STEM
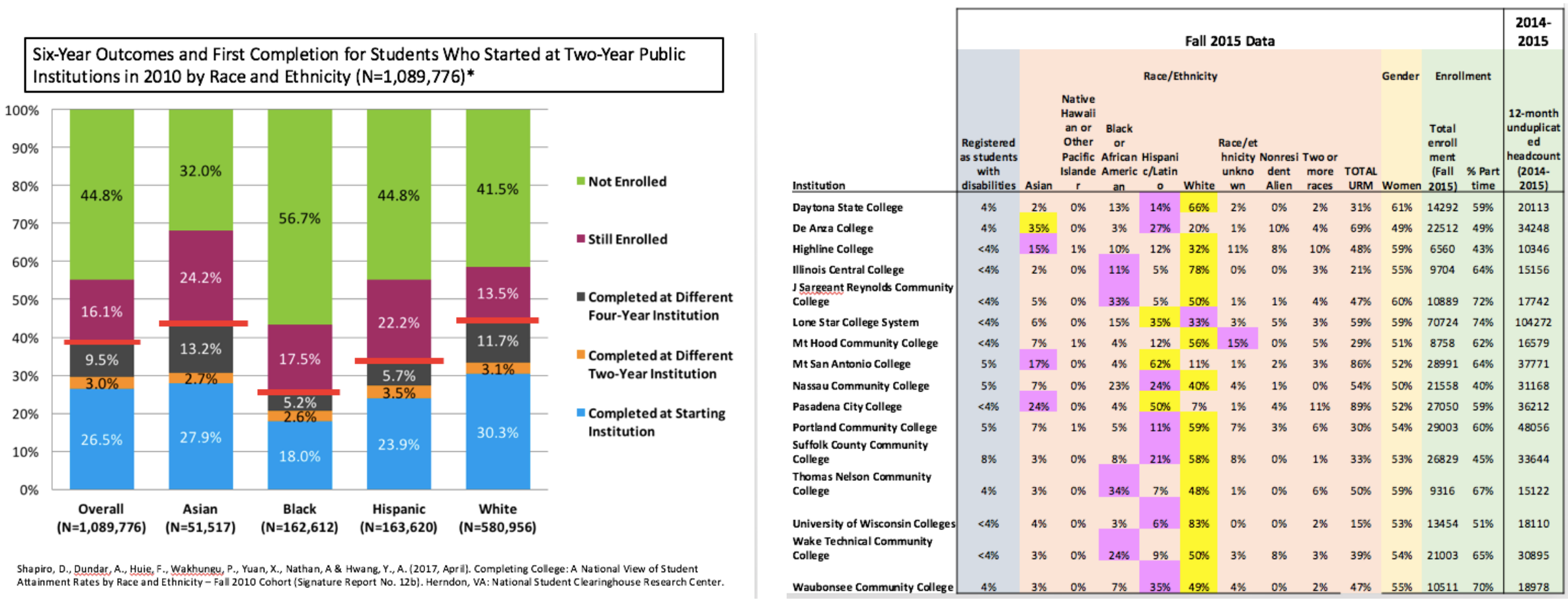


\section{Diversity in action: Broadening participation through strategies for inclusion \\ Gallery walk: Posters about strategies for inclusion}

Develop an Inclusive Community

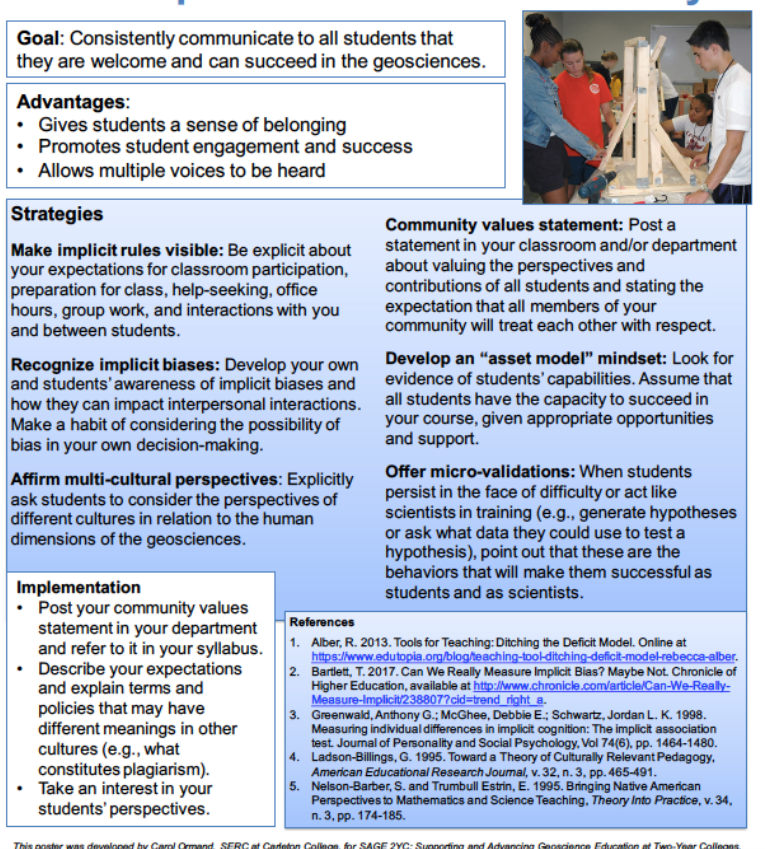

Make implicit rules visible to all students

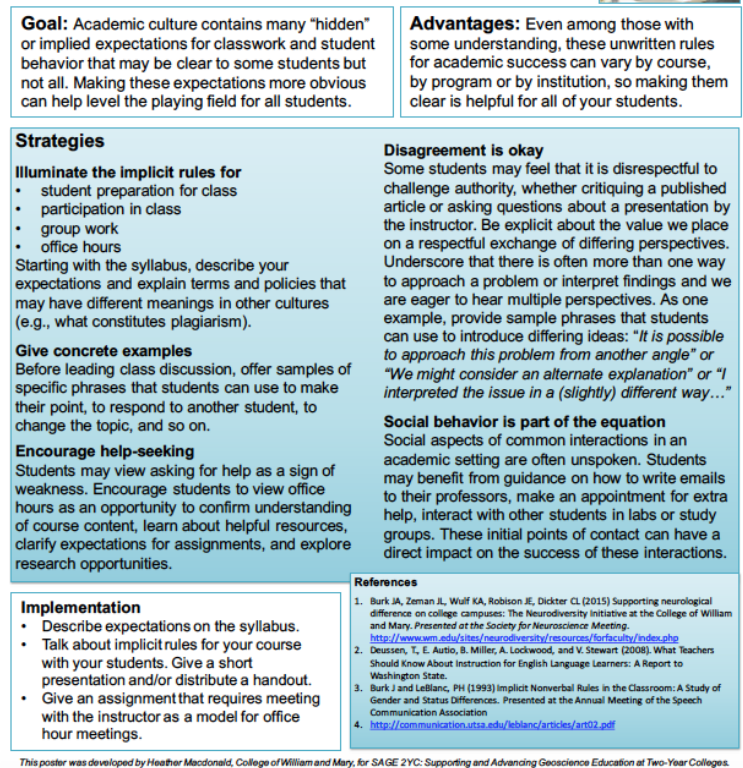

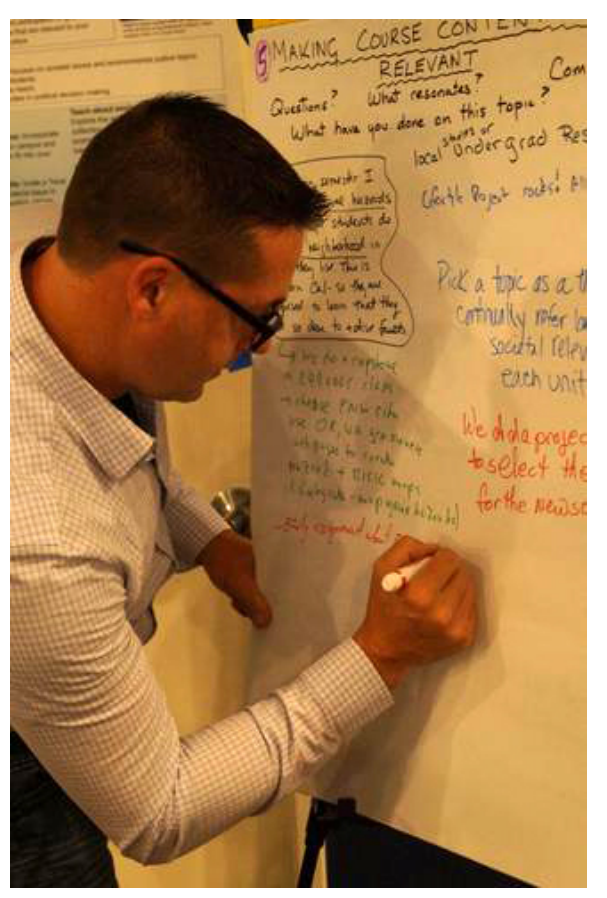




\section{Supporting Students' Sense of Belonging}

Session goals: Participants will

- Be able to define "belonging uncertainty" and describe how it undermines student academic success;

- Know about several key strategies for fostering students' sense of belonging; and

- Have a plan to implement at least one new strategy to foster students' sense of belonging in one or more courses.

Workshop session structure and materials:

3 minutes Reflection

20 minutes Presentation, including a think-pair-share discussion about an intervention 50 minutes Jigsaw using excerpts from research literature

10 minutes Action planning

5 minutes Wrap-up discussion / Q\&A with session leaders 


\section{Supporting Students' Sense of Belonging}

\section{Presentation summarizing key points from the research literature}

\section{Key Findings from the Research on Sense of Belonging}

- Everyone is susceptible to concerns about social belonging

- Belonging uncertainty - is especially strong at transition points, such as moving from high school to college or from a 2 YC to a 4 YCU (Aguilar et al., 2014, Stephens et al., 2014).

- Underrepresented students (including socioeconomic, race, gender, disabilities) are disproportionately susceptible to concerns about social belonging, and these concerns may negatively affect their academic performance (e.g. Aguilar et al., 2014; Walton \& Cohen, 2011)

- Academic and social setbacks, which are a normal part of transitioning to college, can instead feel like evidence of not belonging. This can be compounded by stereotype threat and personal stress.

- There are many tools to foster belonging and normalize transitions have proven effective, including mentoring, peer cohorts, active learning, incornorating examples of diverse scientists, connecting content to careers, infusing societal relavance as we as noncognitive interventions. Short activities in the classroom

- Can dramatically mitigate belonging uncertainty

- Positive GPA impacts

- $\quad$ Benefitall students 


\section{Supporting Students' Sense of Belonging}

Presentation, including a think-pair-share discussion about an intervention

Is this an effective social-psychological intervention? Why or why not?

Professor Jones wants all her students in a class for potential majors to succeed, and she hopes to increase the diversity of geoscientists. So she schedules a weekly help session for students who might be having difficulty, and she personally invites all the women and minority students to attend. (Modified from Aguilar et al., 2014, which has additional examples) 


\section{Supporting Students' Sense of Belonging}

Jigsaw using excerpts from research literature

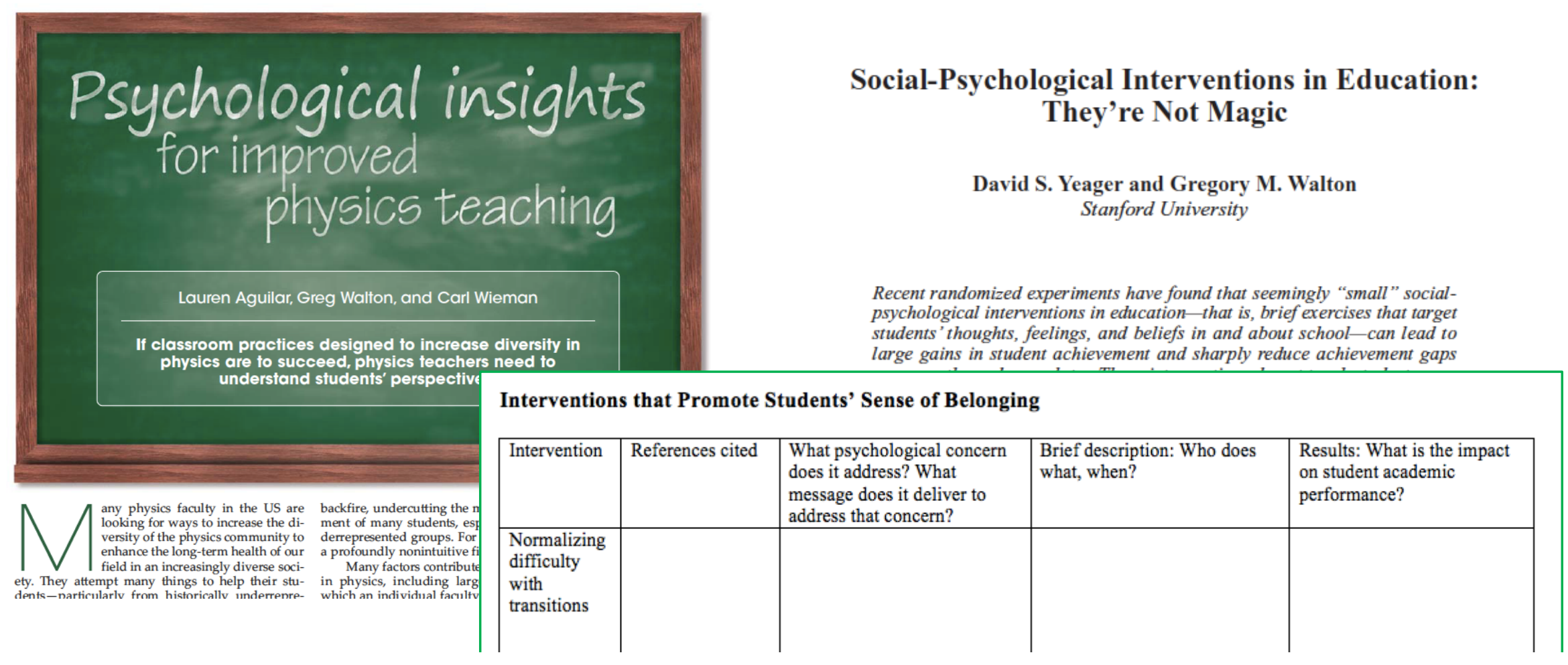

Review of Educational Research June 2011, Vol. 81, No. 2, pp. 267-301 DOI: $10.3102 / 0034654311405999$ ( 2011 AERA. http://rer.aera.net classroom practices designed to increase diversity in Interventions that Promote Students' Sense of Belonging

\begin{tabular}{|l|l|l|l|l|}
\hline Intervention & References cited & $\begin{array}{l}\text { What psychological concern } \\
\text { does it address? What } \\
\text { message does it deliver to } \\
\text { address that concern? }\end{array}$ & $\begin{array}{l}\text { Brief description: Who does } \\
\text { what, when? }\end{array}$ & $\begin{array}{l}\text { Results: What is the impact } \\
\text { on student academic } \\
\text { performance? }\end{array}$ \\
\hline $\begin{array}{l}\text { Normalizing } \\
\text { difficulty } \\
\text { with } \\
\text { transitions }\end{array}$ & & & & \\
\hline
\end{tabular}




\section{Building Students' Science Identity}

Session goals: Participants will learn about and share strategies to

- Infuse career information in class, on-line, and outside of class;

- Develop our students' awareness of the breadth of careers in geoscience; and

- Help our students to identify as scientists.

Workshop session structure and materials:

20 minutes Presentation about science identity, images of geoscientists, and an example of a "geoscientist profile," modeled after Schinske et al.'s "scientist spotlights"

50 minutes Gallery walk about what we can to do help our students build their science identities 


\section{Building Students' Science Identity}

Presentation about science identity, images of geoscientists, and an example of a "geoscientist profile," modeled after Schinske et al.'s "scientist spotlights"

\section{Google image search for GEOSCIENTIST}

What messages do you think these images convey to our students?

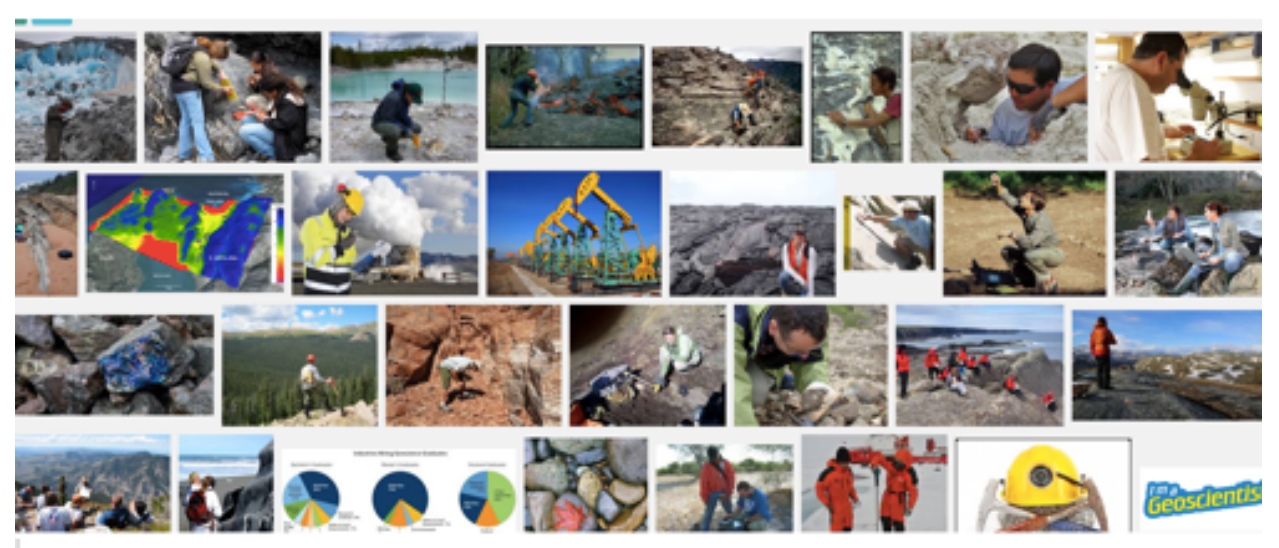

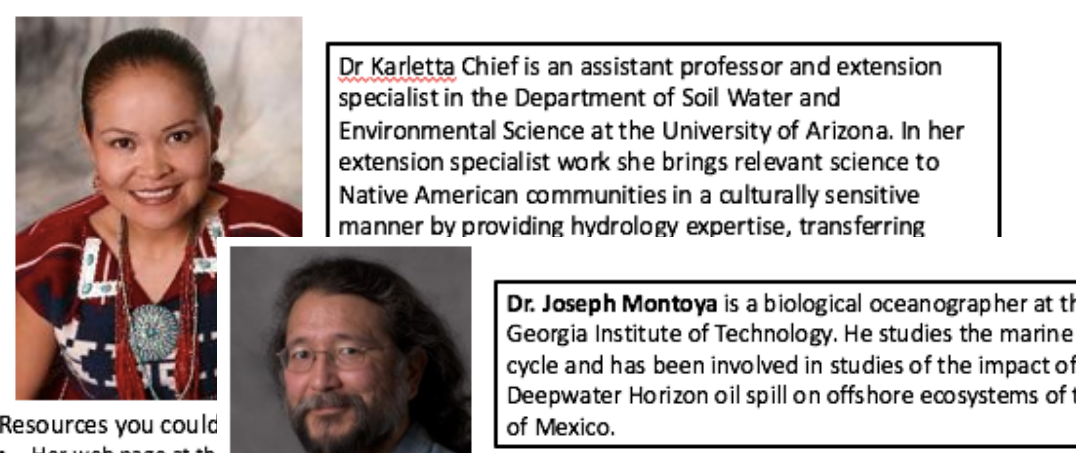

Her web page at th work: https://swes One of her links is t http://arizonaaises, https://wwwwyoutu She co-authored gu https://climatetkw, Sovereignty (Indipe https://wwwyout

Resources you col Webinar for the Nat overview of the mo discusses the Deepv work on natural se development-archiv montoya/

- Web page about his

river input to the so

Resources you could use:

http://mlp.ldeo.colt " The Secret Life of Scientists and Engineers site on Adrienn ocean science. A blc Ph.D. student, it includes several short videos about her lif https://stemseas.wu hth: her linww. pbs.org/wgbh/nova/blogs/secretlife/earth-sc
Dr. Adrienne Block is a Antarctic ice sheets loo How fast can you get r Unce graduating with $h$ number of capacities. $\$$

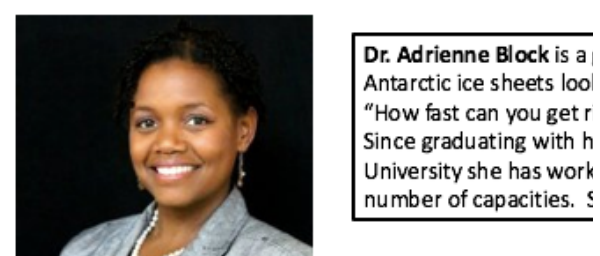




\section{Building Students' Science Identity}

Gallery walk about what we can to do help our students build their science identities

Science Identity questions:

- What can we do in class (seated or online) to develop science identity in our students?

- What can we do outside of class to develop science identity in our students?

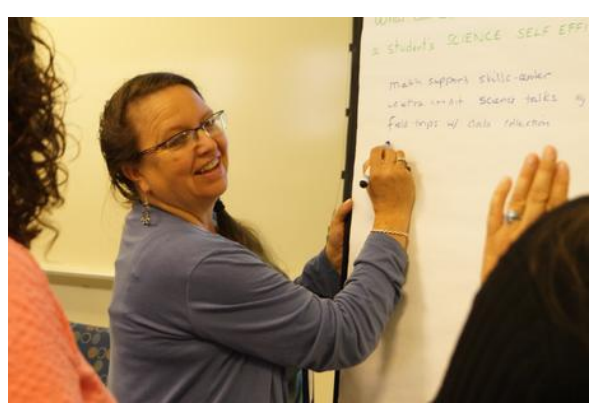

Science Self-Efficacy questions:

- What can we do in class (seated or online) to increase a student's science self- efficacy?

- What can we do outside of class to increase a student's science selfefficacy?

Questions about what Geoscientists do:

- What can we do in class (seated or online) to develop an understanding of what a geoscientist does?

- What can we do outside of class to develop an understanding of what a geoscientist does? 


\section{SAGE Musings}

Growing collection of more than 50 blog posts, 18 of which are relevant to broadening participation in STEM. For example:

- Who has the capacity to succeed in STEM?

- How social-psychological interventions change academic trajectories

- Supporting women in STEM

- The power of affirming your values

- Cultivating students' voices

- Geoscientist biographical sketches

- Women and minorities in science and engineering

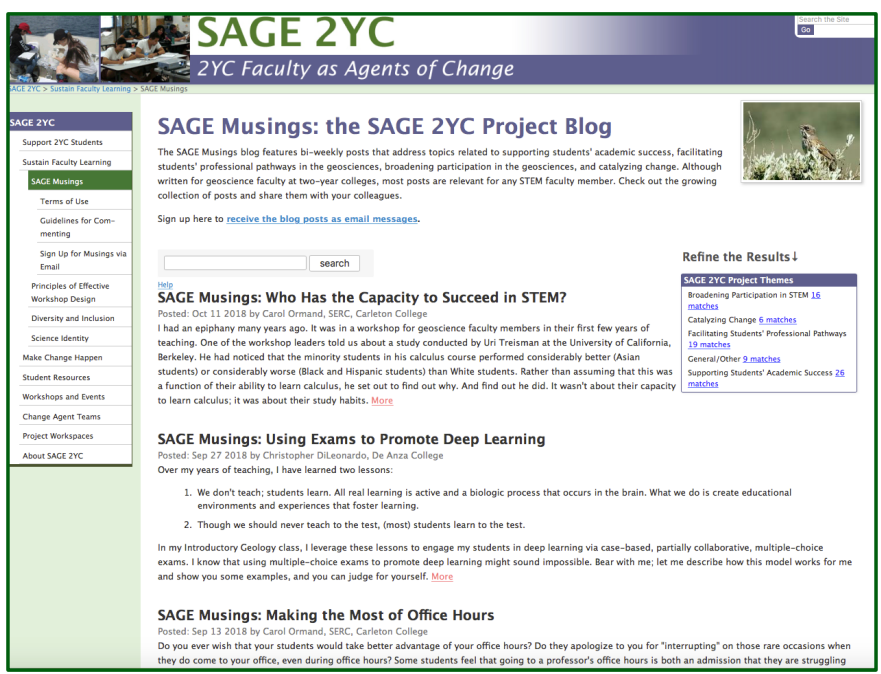

- Evidence-based strategies for mitigating stereotype threat

- Involving students in authentic research

- Micro-validation 


\section{SAGE Musings: Women and Minorities in Science and Engineering}

Carol Ormand, SERC, Carleton College

published May 17, 2017

There's a lot of talk these days about the importance of broadening participation in the STEM disciplines (science, technology, engineering and mathematics). But how much of a problem is there, and how do the geosciences compare to other STEM fields? What subpopulations are under-represented in the geosciences? How under-represented are they? As Huntoon and Lane noted (2007), citing data from the National Science Foundation, "graduates from bachelor's, master's and doctoral degree programs in the geosciences have lower ethnic and racial diversity than do graduates from any other science, technology, engineering, and mathematics (STEM) field." Moreover, the racial and ethnic diversity of people earning geoscience PhDs in the U.S. has not improved since 2004 (Sidder, 2017). Likewise, while women make up more than half of the undergraduate student population, we earn far fewer than half of the undergraduate degrees in STEM disciplines (NSF, 2017) and we comprise only $23 \%$ of the geoscience workforce (Sidder, 2017).

\section{Demographics of the U.S. Population, 2014}

In 2014 (the most recent year for which I could find data), the U.S. population between the ages of 18 and 64 was $62 \%$ White, $17 \%$ Hispanic, $13 \%$ Black or African-American, $6 \%$ Asian, and $2 \%$ all other racial and ethnic groups combined (including, for example, American Indians, Alaska Natives, Native Hawaiians, other Pacific Islanders, and individuals who report more than one race and are not Hispanic) (NSF, 2017). Of course, student populations differ from the overall U.S. population, whether you consider specific institutions or the student population as a whole. In general, however, undergraduate student populations are becoming more diverse. "Most notably, underrepresented minorities, Hispanics in particular, are an increasing fraction of undergraduate students, and whites are a decreasing fraction. In all racial and ethnic groups, more women than men enroll in college" (NSF, 2017).

Racial and Ethnic Diversity in Science and Engineering, 2014

People who identify as Hispanic, Black or African-American, Native Americans, Pacific Islanders, or multi-racial constitute about one-third of the U.S. population, and are under-represented minorities in the STEM disciplines. What we mean when we say that they are under-represented

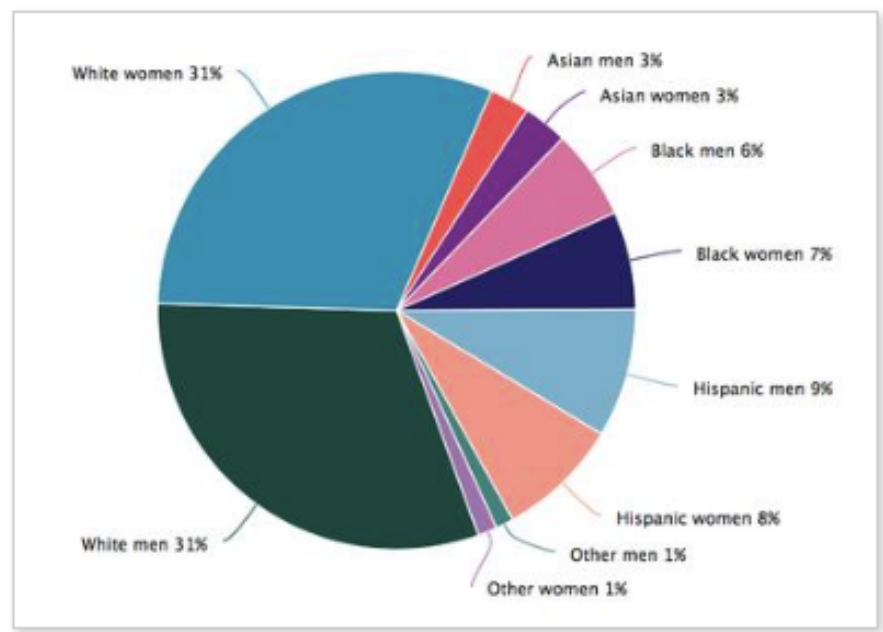

Resident population of the United States ages $18-64$, by race, ethnicity, and sex: 2014. Data from the National Science Foundation, 2017. 


\section{Resources for the Geoscience Community}

- Materials for professional development workshops

- Diversity in action: Broadening participation through strategies for inclusion

- Supporting students' sense of belonging

- Building students' science identity

- SAGE Musings

- Growing collection of $>50$ posts, 18 of which are relevant to broadening participation in STEM

- and more on the project website: https://serc.carleton.edu/sage2yc/index.html
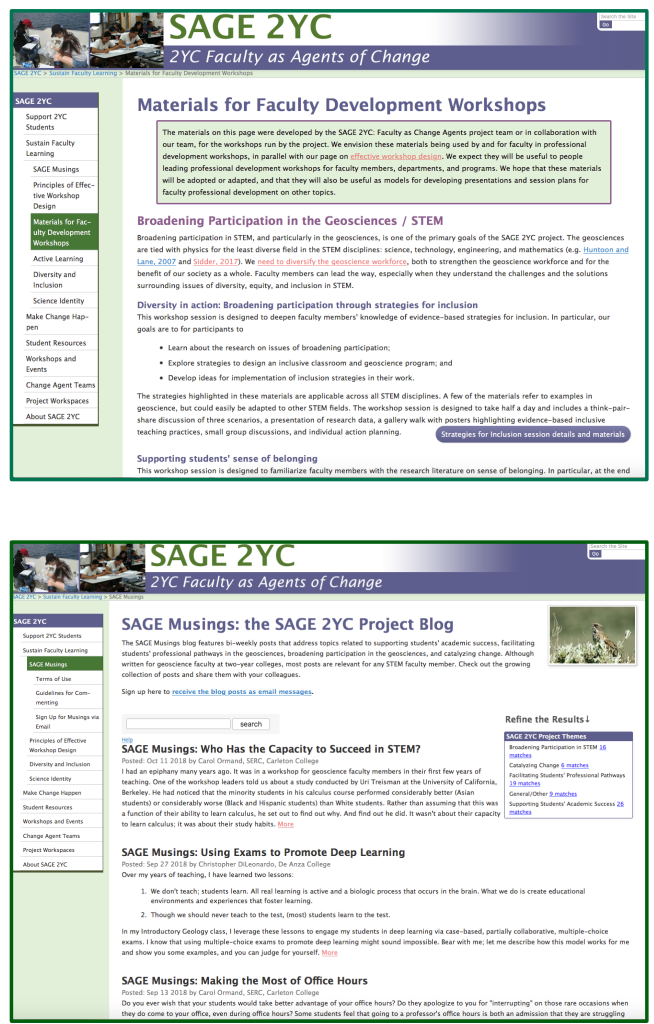


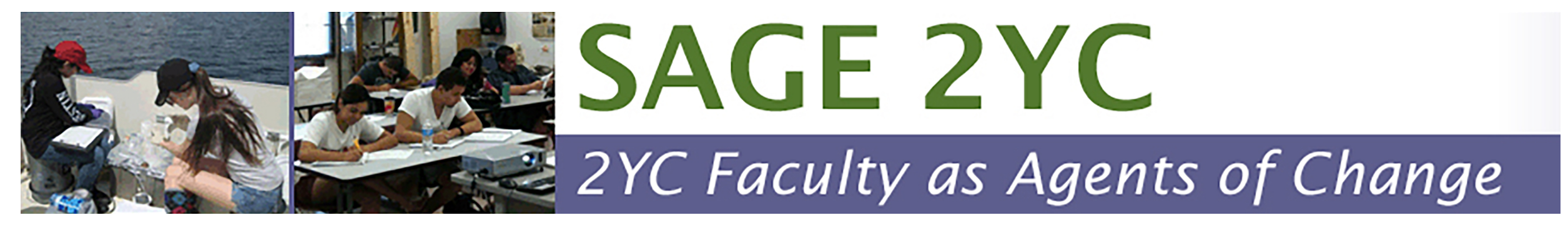

https://serc.carleton.edu /sage2yc/index.html

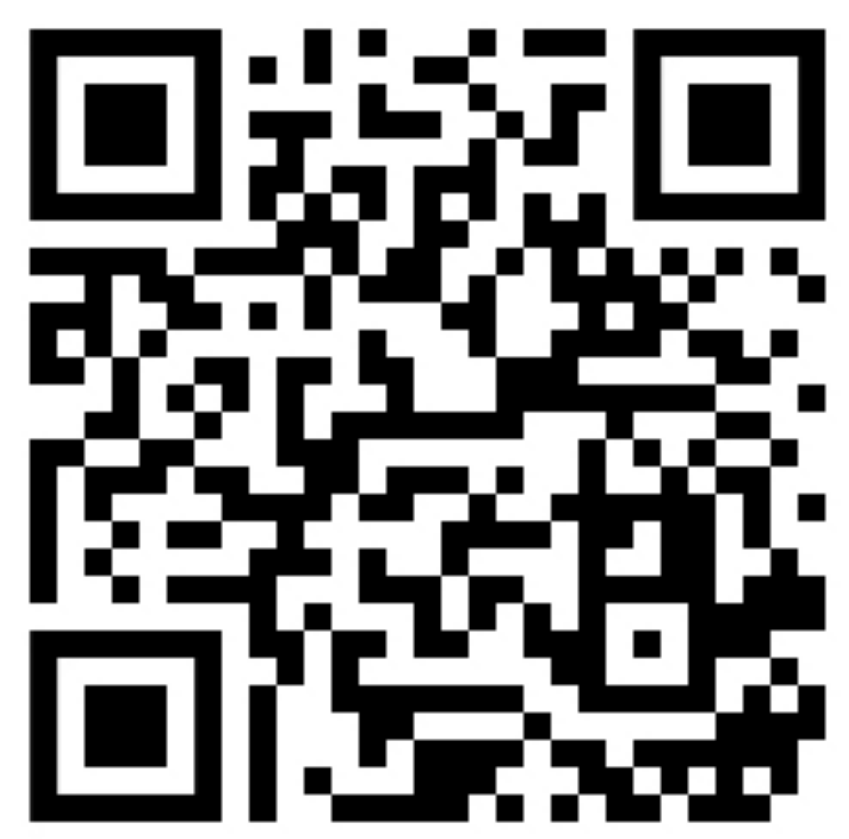

